\title{
The number of circulating endothelial progenitor cells from septic patients are associated with different infectious organisms
}

\author{
Yingying Zhu \\ Shandong University Cheeloo College of Medicine Shandong Provincial Hospital \\ Nana Yang ( $\sim$ benben1980@126.com) \\ Weifang Medical University \\ Jing Zhu \\ Shandong Laboratory Animal Center of Shandong First Medical University \\ Chao Fu \\ Taian City Central Hospital \\ Xinghan Tian \\ Qindao University Medical College Affiliated Yantai Yuhuangding Hospital \\ Fusen Zhang \\ Taian City Central Hospital \\ Lei Zhao \\ Taian City Central Hospital \\ Jingwei Zhu \\ Taishan District Maternal and Child Health and Family Planning Serivce Center \\ Kaixuan Lv \\ Weifang Medical University \\ Chunting Wang \\ Shandong University Cheeloo College of Medicine Shandong Provincial Hospital
}

\section{Research}

Keywords: Sepsis, Septic patients, endothelial progenitor cells, infection

Posted Date: June 17th, 2020

DOI: https://doi.org/10.21203/rs.3.rs-35856/v1

License: (c) (i) This work is licensed under a Creative Commons Attribution 4.0 International License. Read Full License

Version of Record: A version of this preprint was published at Annals of Palliative Medicine on January 1st, 2021. See the published version at https://doi.org/10.21037/apm-20-2458. 


\section{Abstract}

Background Endothelial progenitor cells (EPCs) can affect the repairment of endothelial injury by improving the process of reendothelialization and angiogenesis in sepsis patients. However, the markers of EPCs have not been standardized nowadays, and the changes of EPCs are still unclear in patients with different infectious organisms. This study explored the relationship between the number of EPCs and different infectious organisms in patients with sepsis. Materials and Methods 39 septic patients and 20 healthy controls were enrolled in this study. The number of CD34+/KDR+, CD133+/KDR+, CD34+/CD133+/KDR+, CD34+, CD133+, and KDR+ cells were all analyzed through flow cytometry. Analysis of adhesion function of EPCs were also performed by counting the number of adherent cells in different cultured time points ( 4 days, 14 days, and 21 days). Results The number of EPCs in peripheral blood of septic patients were higher than that of healthy controls, but there were no significant differences between sepsis group and septic shock group, also between the survival group and the nonsurvival group. Additionally, the percentages of CD34+/CD133+/KDR+ cells in Gram-positive bacteremia group was significantly higher than the Gram-negative bacteremia group and negative blood culture group; the percentage of KDR+ cells in both Gram-positive bacteremia group and Gram-negative bacteremia group were significantly higher than the negative blood culture group. Furthermore, the adhesion function of EPCs in healthy controls was significantly higher than in septic patients. Conclusions The number of circulating EPCs and the adhesion function of EPCs in patients with sepsis are associated with different infectious organisms.

\section{Background}

Sepsis is a serious complication of critically ill patients with infection, burn/wound, shock, etc [1-3]. The damage of endothelium barrier and microcirculatory disturbance, such as cell separation, cell ablation, changes in vasomotor function and apoptosis, etc., are important pathological mechanisms, which contribute to the development of multiple organ failure $[4,5]$. Therefore, repairment of endothelial damage plays an important role in the treatment of sepsis [6-8].

Endothelial progenitor cells (EPCs) have a highly differentiated proliferative capacity in the pathogenesis of severe sepsis, which can repair damaged endothelial cells [9-11]. Through mobilization, proliferation囚adhesion\migration, homing to damaged blood vessels, EPCs can repair the damaged vascular intima, promote the formation of neovascularization to improve the ischemia and hypoxia of local tissues and organs, and reduce the inflammatory response[12-14]. Increasing in the number and function of EPCs provide a new treatment for sepsis [15, 16].

In the past decades, the effect of sepsis on the number of EPCs in patients peripheral blood had been different. In 2007, Mayr et al. found that the number of EPCs in healthy volunteers decreased significantly after infusion of $2 \mathrm{ng} / \mathrm{Kg}$ lipopolysaccharide (LPS) [17],while recent studies have shown that the number of EPCs in patients with severe sepsis was significantly elevated and negatively correlated with mortality [18-20]. Patschan et al. found that the numbers of CFU-ECs (colony-forming unit endothelial cells) was lower in patients with sepsis than in healthy controls [21]. While Changes in the number and function of EPCs in patients with sepsis caused by different infectious orgnisms are still unclear. In this paper, the septic patients were divided into three groups: negative blood culture, Gram-negative bacteria and Gram-positive bacteria, the changes of the number of EPCs in peripheral blood and the changes of EPCs proliferation and adhesion functions were detected and analyzed in different groups of patients.

\section{Materials And Methods}

\section{Study Patients}

Thirty-nine patients with sepsis admitted to the intensive care unit (ICU) at the Taian City Central Hospital were included between February 2017 and July 2017 (screening outlined in table 1). The hospital's medical ethics committee approved the study protocol, and all of the patients provided written informed consent. We defined sepsis as life-threatening organ dysfunction caused by a dysregulated host response to infection. Patients with septic shock were identified by a vasopressor requirement to maintain a mean arterial pressure of $>65 \mathrm{mmHg}$ and serum lactate level greater than $2 \mathrm{mmol} / \mathrm{L}$ ( $>18 \mathrm{mg} / \mathrm{dL}$ ) in the absence of hypovolemia [22]. Patients had to be over 18 and below 80 years old,

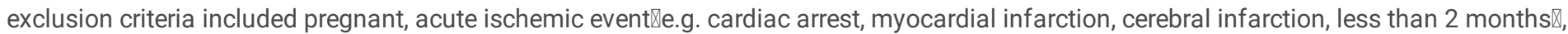
history of metastatic cancer or autoimmune diseases or other situations that the host immunity was inhibited. For clinical characterization the Acute Physiology and Chronic Health Evaluation (APACHE) II and Sepsis-Related Organ Failure Assessment (SOFA) scores were calculated on admission. Age- and gender-matched healthy subjects $(n=20)$ were included as a control group. They were without any known cardiovascular risk factor or diseases and did not take any medications.

\section{Blood Culture}

Blood culture was drawn before the start of antimicrobial therapy or at the onset of fever and analyzed according to local standards. Blood culture results were carefully assessed by the treating physicians and if no bacterial growth was detected within the incubation period, the blood culture was considered negative. Pathogens were grouped into Gram-positive bacteria, Gram-negative bacteria. Depending on blood 
culture results, patients were classified into 3 following groups: negative blood culture, Gram-negative bacteremia, Gram-positive bacteremia. Patients in the "Gram-negative bacteremia" group were infected by these organisms: Escherichia coli, Klebsiella, Enterobacter cloacae, and Acinetobacter baumannii. The "Gram-positive bacteremia" group included the following organisms: Staphylococcus aureus and Staphylococcus hominis. The treating physician retrospectively determined the focus of the infection based on all available clinical and microbiological data. For analysis, the infections were divided into six categories (pneumonia, urethritis, peritonitis, pancreatitis, skin/soft tissue infection and others).

\section{Blood sampling and flow cytometry}

Human blood samples were collected in heparin anticoagulant tubes through venipuncture, and peripheral blood mononuclear cells (PBMC) were obtained by density gradient centrifugation with Ficoll $(1.077 \mathrm{~g} / \mathrm{ml}$; Sigma). At last, PBMC were incubated for $30 \mathrm{~min}$ at room temperature in a dark room with appropriate concentrations of the following monoclonal antibodies: Alexa Fluor 647 conjugated KDR (BD Biosciences), FITC conjugated CD34 (eBioscience), PE conjugated CD133 (eBioscience). Appropriate isotype controls were used. Samples were assessed by flow cytometer with FACS Cell Quest analysis software (Becton-Dickinson, CA, USA). At least 1,000,000 events were recorded in the mononuclear cell gate set on the SSC/FSC morphological plot, and the results were analyzed by FlowJo V10 software (Tree Star Inc, Ashland, USA).

\section{Endothelial progenitor cell culture}

PBMC obtained by density gradient centrifugation were seeded on fibronectin (Corning)-coated plates in order to evaluate cell's function. 2 million cells per well were seeded in 24-well plates, and 4 million cells per well were seeded in 12-well plates. Cells were cultured in EGM2(Lonza), after 4 days, non-adherent cells were removed, and fresh mediums were added. The culture was maintained through day 21 , and adherent cells were subjected to further examinations.

\section{Characterization of EPCs}

After cultured for 7 days, cells seeded in 24-well plates were incubated with $2.5 \mathrm{mg} / \mathrm{L}$ Dil-ac-LDL (Thermo Fisher Scientific Inc.) for $2 \mathrm{~h}$ at $37^{\circ} \mathrm{C}$ and $10 \mathrm{mg} / \mathrm{L}$ FITC-UEA (Sigma-Aldrich) for $1 \mathrm{~h}$ at $37^{\circ} \mathrm{C}$, and then fixed for $5 \mathrm{~min}$ with $1-2 \%$ paraformaldehyde (Sigma-Aldrich). Double positive cells and total cell numbers were counted in five random fields.

\section{Cell adhesion}

EPCs cultured in 12-well plates were vigorously washed three times with PBS, and the number of adherent cells were calculated as the average of five fields counted by independent blinded investigators on day $4 \llbracket$ day 12 , day 21 under a microscope (magnified $100 \times$ ).

\section{Statistical analysis}

All data were presented as mean \pm SD or SEM. Intergroup comparisons were performed by paired Student t tests or Mann-Whitney tests. Statistical significance was considered as $p<0.05$.

\section{Results}

\section{Demographics of septic patients and the healthy controls.}

For this study, 39 septic patients and 20 healthy controls were enrolled based on the inclusion and exclusion criteria. A summary of the clinical data was presented in Table 1. Except for differences in the white blood cell, platelet and hemoglobin ( $p<0.01$, Table 1), there was no significant demographic differences between the healthy controls and the septic patients. Patients who suffered septic shock had significantly increased APACHE II scores (23.3 \pm 6.6 vs. $18.2 \pm 8.8, p<0.05)$, SOFA scores $(9.2 \pm 2.8$ vs. $5.1 \pm 2.5, p<0.01)$, lactate $(3.8 \pm 3.1$ vs. $2.1 \pm 1.3, p<$ $0.05)$ and PCT $(62.6 \pm 75.9$ vs. $26.4 \pm 50.1, p<0.05)$ and significantly decreased platelet $(112.1 \pm 50.6$ vs. $137.0 \pm 73.9, p<0.05)$ compared with patients who had sepsis. Compared with patients who were survivors, patients who died had significantly increased APACHE II scores (26.6 \pm 6.4 vs. $17.5 \pm 7.5, p<0.01)$, and significantly decreased Hospital length of stay (LOS) $(12.2 \pm 14.6$ vs. $25.4 \pm 25.1, p<0.01)($ Table 1$)$.

Baseline characteristics also revealed that, 16 patients (41.0\%) had septic shock and 12 patients (30.8\%) died in the hospital. But the mortality, ICU LOS and Hospital LOS were not significantly different between sepsis and septic shock patients. In patients, the most common infection was peritonitis $(43.6 \%, 17 / 39)$, followed by pneumonia $(17.9 \%, 7 / 39)$, urethritis, peritonitis, skin/soft tissue infection and others. Bacteremia was observed in 18 patients (46.2\%), and of which gram-positive bacteria accounted for 5 cases, gram-negative bacteria accounted for 13 cases.

\section{Characterization of EPCs}


Because EPCs could take up LDL and bind lectin, taking up LDL and binding lectin were considered as differentiation markers of EPCs. In this study the ratios of double-positive cell numbers in patients had no significant difference compared with healthy controls, and both were greater than 95\% (Fig.1A\&D-F). And EPCs showed a cobblestone-like morphology cultured for 10 days in EGM-2 medium (Fig.1B, C).

\section{The number of EPCs in septic patients was more than that in healthy controls}

EPCs were absent of uniform specific phenotypic markers in present studies. Asahara et al used CD34 and KDR markers to identify EPCs for the first time [23]. CD34 was a marker of hematopoietic stem cells, and KDR was a receptor for VEGF and played an important role in the homing of EPCs. In order to differentiate the mature endothelial cells (ECs) from EPCs, CD133, an undifferentiated marker, was used to identify undifferentiated EPCs [24]. In this study, six subpopulations of progenitor cells: single-positive (CD34+ ,CD133+ and KDR+) cells, bi-positive (CD34+/KDR+ and CD133+/KDR+) cells and triple-positive (CD34+/CD133+/KDR+) cells were all detected in all groups.

The levels of CD34+/KDR+, CD133+/KDR+, CD34+/CD133+/KDR+, CD34+, CD133+, and KDR+ progenitor cells in septic patients were significantly higher than that in healthy controls $(0.1027 \pm 0.0190$ vs. $0.0270 \pm 0.0073 P \llbracket 0.01,0.0215 \pm 0.0036$ vs. $0.0025 \pm 0.0006 P<0.01$, $0.0086 \pm 0.0016$ vs. $0.0003 \pm 0.0001 \mathrm{P}<0.01,0.9208 \pm 0.1322$ vs. $0.2777 \pm 0.0646 \mathrm{P}<0.01,0.2636 \pm 0.0444$ vs. $0.0370 \pm 0.0072 \mathrm{P}<0.01$, $0.2176 \pm 0.0292$ vs. $0.0727 \pm 0.0178 \mathrm{P}<0.01$, [mean $\pm \mathrm{SEM}, \%$ of total PBMC]) (Fig.2).

Patients were further divided into sepsis group and septic shock group, and analysis of EPCs markers showed that there were no statistically differences between the two subgroups, although all the levels of progenitor cells markers in the septic shock group were lower than those in the septic group (Fig.3). Rafat et al. found that the number of EPCs in septic non-survival group was significantly lower than that in septic survival group [25]. In this paper, the datas showed that the number of EPCs in the septic survival group were similar as that in the septic nonsurvival group (Fig.4).

\section{The levels of EPCs subpopulations were different respectively in positive blood cultures group,negative blood cultures group and healthy controls.}

Depending on the results of blood culture, the septic patients were divided into positive blood cultures group and negative blood cultures group. Datas showed that the percentage of KDR-positive cells in PBMC in positive blood cultures group was significantly higher than the negative blood cultures group ( $0.3260 \pm 0.0476$ vs. $0.1246 \pm 0.0206 \mathrm{P} \otimes 0.01$, [mean $\pm \mathrm{SEM}, \%$ of total PBMC]) (Fig.5). Although the percentages of $\mathrm{CD} 34+/ K D R+\square C D 133+/ K D R+\square C D 34+/ C D 133+/ K D R+\square C D 34+$ progenitor cells were higher in positive blood cultures group than in negative blood cultures group, the difference didn't have the significance.

\section{The levels of EPCs subpopulations were different respectively in Gram-positive bacteremia group, Gram-negative bacteremia group, andnegative blood culture group.}

Endotoxin (LPS, a major component of the outer membrane of Gram-negative bacteremia) was often used to make sepsis models [26], while according to the results of blood culture, the septic patients in clinical study were usually divided into negative blood culture, Gram-positive bacteremia, Gram-negative bacteremia etc. At present, pathogenic bacteria that caused sepsis had not classified in the study of the numbers of EPCs in septic patients. According to the results of blood culture, the septic patients in this study were divided into three groups as described above. In 39 septic patients, 21 patients had negative microbial results, 18 patients were positive for blood culture, of which 13 were Gramnegative bacteremia, and 5 were Gram-positive bacteremia. Analysis of the number of EPCs in different groups of patients, showed that the percentage of CD34+/CD133+/KDR+ cells in PBMC in Gram-positive bacteremia group(G+) was significantly higher than the Gram-negative

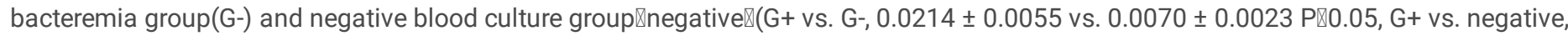

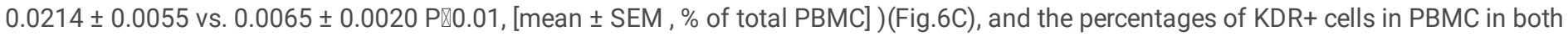
Gram-positive bacteremia group and Gram-negative bacteremia group were significantly higher than the negative blood culture group (G-vs. negative, $0.3083 \pm 0.0632$ vs. $0.1246 \pm 0.0206 \mathrm{P} \otimes 0.01, \mathrm{G}+$ vs. negative, $0.3722 \pm 0.0526$ vs. $0.1246 \pm 0.0206 \mathrm{P} \otimes 0.01$, [mean $\pm \mathrm{SEM}$, \%of total PBMC])(Fig. 6F).

\section{The number of EPCs in healthy controls was significantly more than in septic patients respectively in 4 days, 14 days and 21 days culture}

PBMC derived from patients were cultured on fibronectin-coated plates, and the numbers of EPCs were counted at 4,14 and 21 days respectively. Depending on the results of blood culture, the septic patients were divided into positive blood cultures group and negative blood cultures group. Results showed that the number of EPCs cultured on 4,14 and 21 days in both the two groups were significantly less than that in heathy controls (Fig.7A-C). However, no significant differences was observed between the two groups (Fig.7A-C).

To further analyze whether the number of EPCs was associated with Gram-positive bacteria or Gram-negative bacteria, the septic patients in this study were divided into three groups as described above. According to the results of blood culture, there were no significant differences among the three groups (Fig.7D-F). 


\section{Discussion}

During sepsis, an increase of circulating endothelial cells (ECs) were found by Mutunga et al., which demonstrated that endothelial barrier was damaged leading to microvascular dysfunction [27]. Because of the limited ability of proliferation, terminally differentiated ECs are not sufficient to repair severe vascular damage resulting in different organs dysfunction. EPCs have been shown to possess the potential to repair vascular endothelial damage in sepsis, acute respiratory distress syndrome, hindlimb ischemia and cardiovascular and cerebrovascular diseases. Fan et al. has verified that exogenous administration of EPCs is beneficial in cercal ligation and puncture (CLP) induced sepsis, and it can improve lung vascular integrity and reduce mortality in sepsis [28]. We have found that LPS induced lung injury repairment may be correlated with improvement of EPCs numbers and functions induced by high density lipoprotein mimetic peptide reverse-D-4F [29]. EPCs may be a therapeutic target for sepsis induced lung impairment in the future.

At present, EPCs markers are controversial, and different markers of EPCs have been used in different research groups. CD34, CD133 and KDR are often used as the surface markers of EPCs. CD133 is a marker of progenitor cells, and it can exclude mature ECs from progenitor cells. CD34 is presented in both hematopoietic stem cells (HSCs), EPCs and mature ECs, thus CD34+/CD133+ EPCs include some HSCs. KDR is another endothelial marker required in definition of EPCs. In this study, CD34+/CD133+/KDR+ cells were used to identify EPCs phenotype, and the number of CD34+/KDR+, CD133+/KDR+, CD34+/CD133+/KDR+, CD34+, CD133+, and KDR+ cells were all analyzed through flow cytometry.

In this study, the levels of CD34+/KDR+, CD133+/KDR+, CD34+/CD133+/KDR+, CD34+, CD133+, and KDR+ progenitor cells in septic patients were significantly higher than those in healthy controls, which is consistent with the observations of Rafat et al, and their datas showed that the number of EPCs (CD34+/CD133+/KDR+) was correlated with survival in septic patients [25]. In pediatric sepsis, the levels of EPCs(CD34+/CD144+/CD133+) in the survival patients were significantly higher than in non-survival patients [30]. While there were no differences in circulating EPCs(CD133+/KDR+) between septic non-survival patients and septic survival patients in Patschan et al. research [21]. The reasons of different results obtained by different researchers may be different blood collection time, different phenotype of EPCs, different criteria for patient selection etc. In this study, the number of CD34+/KDR+, CD133+/KDR+, CD34+/CD133+/KDR+, CD34+, CD133+, and KDR+ cells in both survival patients and non-survival patients were measured through flow cytometry, and datas showed that there was no significantly different between two groups.

Becchi et al. further classified septic patients as septic patients and severe septic/septic shock patients, and have found that the percentage of CD133+/KDR+ cells in CD34+ cells in severe septic/septic shock patients is significantly higher than that in septic patients [31]. In order to further analysis of the contribution of EPCs numbers to the development of sepsis, the septic patients were divided into septic group and septic shock group. Results showed that the levels of CD34+/KDR+, CD133+/KDR+, CD34+/CD133+/KDR+, CD34+, CD133+, and KDR+ cells in septic group were similar as that in the septic shock group. The difference between our findings and that of Becchi et al. may be due to different counting methods for EPCs and different inclusion criteria used in the subgroups. CD34+/KDR+, CD133+/KDR+, $\mathrm{CD} 34+/ \mathrm{CD} 133+/ \mathrm{KDR}+, \mathrm{CD} 34+, \mathrm{CD} 133+$, and KDR+ cells counts in this study were expressed as percentage of PBMC, while EPCs counts were expressed as percentage of $\mathrm{CD} 133+/ \mathrm{KDR}+$ cells in the CD34+ population in another study performed by Becchi et al. The number of patients included in both our study and Becchi et al. research was relatively small, so the larger sample of sepsis population in the future would be needed to analyze the different contribution of EPCs to septic patients with shock or not.

Current studies of EPCs numbers in septic patients have not further analyzed by the organisms of infection. Depending on the results of blood culture, the septic patients were further divided into negative blood culture, Gram-positive bacteremia, Gram-negative bacteremia in this study. Results showed that the percentages of KDR+ cells in PBMC in both Gram-positive bacteremia group and Gram-negative bacteremia group were significantly higher than the negative blood culture group, and the percentage of CD34+/CD133+/KDR+ cells in PBMC in Gram-positive bacteremia group was significantly higher than the Gram-negative bacteremia group and the negative blood culture group. Although the number of patients was relative small, EPCs numbers in peripheral blood showed difference according to different infectious organisms. In the article of Menchinelli et al. [32], the mediantime-to-detection (TTD) for Gram-negative species was 9.3-12.0h, the TTD for Gram-positive species was 13.5-15.5h, so the diagnosis of bacteremia was often delayed in sepsis clinical treatment. In our study, the time-to-detection of the percentages of EPCs in PBMC was only 2-3h, and the result showed that, the percentages of KDR+ and CD34+/CD133+/KDR+ were positively correlated with the organisms of blood culture. Further large population experiments should be needed to establish the diagnostic criteria.

CFU-ECs (colony-forming unit endothelial cells) assay is widely used to evaluate proliferation of 'early outgrowth' EPCs, while the method needs more peripheral for CFU assay, and is difficult to achieve. In this study, PBMC derived from patients peripheral blood were cultured on fibronectin-coated plates, and the number of EPCs were counted for 4,14 and 21 days respectively, which was used to try to evaluate EPCs proliferation and adhesion. Results showed that the numbers of EPCs cultured in 4,14 and 21 days were significantly more in heathy controls than in septic patients and had no relationship with the organisms of infection. This method is easy to achieve, while further experiments will be needed to demonstrate whether the method can be used to estimate the proliferation and adhesion function of EPCs.

Page 5/14 
In conclusion, we have demonstrated here for the first time that the percentages of CD34+/CD133+/KDR+ cells in Gram-positive bacteremia patients was significantly higher than the Gram-negative bacteremia and negative blood culture patients, and the percentage of KDR+ cells in bacteremia patients was significantly higher than the non-bacteremia patients. Based on this, we suggest that EPCs may be a new early indicator for the differential diagnosis of blood culture organisms in sepsis patients, which can help to give a quick guideline for clinical treatment decisions. Further animal and population experiments will be needed to testify our findings involved and to deduce possible therapeutic implications to improve sepsis outcome.

\section{Declarations}

\section{Ethics approval and consent to participate}

The medical ethics committee of Taian City Central Hospital approved the study protocol, and all of the patients provided written informed consent.

\section{Consent for publication}

All list authors consent to the submission and all data are used with the consent of the person generating the data.

\section{Availability of data and materials}

All data generated or analysed during this study are included in this published article.

\section{Competing interests}

The authors declare that they have no competing interests.

\section{Funding}

This study was supported by the National Natural Science Foundation of China (No. 81600360), the Province Natural Science Foundation of Shandong (No. ZR2012HL18), the Province Science and Technology Development Foundation of Shandong (2014GSF118105), the Province Higher University Science and Technology Development Project of Shandong (No. J14LK03) and the Science and Technology Development Project of Taian (No. 2018NS0160)

\section{Authors' contributions}

YYZ, JZ, NNY and CTW had full access to all data in the study, and take

responsibility for integrity and accuracy of all data and data analyses. YYZ, CF, KXL and NNY contributed substantially to the study design, data analysis and interpretation, and writing of the manuscript.

All authors read and approved the final manuscript.

\section{Acknowledgements}

Not applicable.

\section{References}

1. Gill SE, Rohan M, Mehta S: Role of pulmonary microvascular endothelial cell apoptosis in murine sepsis-induced lung injury in vivo. Respir Res 2015, 16:109.

2. Ammer-Herrmenau C, Kulkarni U, Andreas N, Ungelenk M, Ravens S, Hubner C, Kather A, Kurth I, Bauer M, Kamradt T: Sepsis induces longlasting impairments in CD4+ T-cell responses despite rapid numerical recovery of T-lymphocyte populations. Plos One 2019, 14(2):e211716.

3. Belba MK, Petrela EY, Belba AG: Epidemiology and outcome analysis of sepsis and organ dysfunction/failure after burns. Burns 2017, 43(6):1335-1347.

4. Goldenberg NM, Steinberg BE, Slutsky AS, Lee WL: Broken barriers: a new take on sepsis pathogenesis. Sci Trans/ Med 2011, 3(88):25p$88 p$.

5. Osuchowski MF, Welch K, Siddiqui J, Remick DG: Circulating cytokine/inhibitor profiles reshape the understanding of the SIRS/CARS continuum in sepsis and predict mortality. J Immunol 2006, 177(3):1967-1974. 
6. Mu S, Liu Y, Jiang J, Ding R, Li X, Li X, Ma X: Unfractionated heparin ameliorates pulmonary microvascular endothelial barrier dysfunction via microtubule stabilization in acute lung injury. Respir Res 2018, 19(1):220.

7. Barabutis N, Khangoora V, Marik PE, Catravas JD: Hydrocortisone and Ascorbic Acid Synergistically Prevent and Repair Lipopolysaccharide-Induced Pulmonary Endothelial Barrier Dysfunction. Chest 2017, 152(5):954-962.

8. Leligdowicz A, Richard-Greenblatt M, Wright J, Crowley VM, Kain KC: Endothelial Activation: The Ang/Tie Axis in Sepsis. Front Immunol 2018, 9:838.

9. Cribbs SK, Sutcliffe DJ, Taylor WR, Rojas M, Easley KA, Tang L, Brigham KL, Martin GS: Circulating endothelial progenitor cells inversely associate with organ dysfunction in sepsis. Intensive Care Med 2012, 38(3):429-436.

10. Schlichting DE, Waxman AB, O'Brien LA, Wang T, Naum CC, Rubeiz GJ, Um SL, Williams M, Yan SC: Circulating endothelial and endothelial progenitor cells in patients with severe sepsis. Microvasc Res 2011, 81(2):216-221.

11. Zhou Y, Li P, Goodwin AJ, Cook JA, Halushka PV, Chang E, Fan H: Exosomes from Endothelial Progenitor Cells Improve the Outcome of a Murine Model of Sepsis. Mol Ther 2018, 26(5):1375-1384.

12. Sun R, Huang J, Sun B: Mobilization of endothelial progenitor cells in sepsis. Inflamm Res 2020, 69(1):1-9.

13. Padfield GJ, Tura O, Haeck ML, Short A, Freyer E, Barclay GR, Newby DE, Mills NL: Circulating endothelial progenitor cells are not affected by acute systemic inflammation. Am J Physiol Heart Circ Physiol 2010, 298(6):H2054-H2061.

14. Vandoorne K, Rohde D, Kim H, Courties G, Wojtkiewicz G, Honold L, Hoyer FF, Frodermann V, Nayar R, Herisson F et al: Imaging the Vascular Bone Marrow Niche During Inflammatory Stress. Circ Res 2018, 123(4):415-427.

15. Fan H, Goodwin AJ, Chang E, Zingarelli B, Borg K, Guan S, Halushka PV, Cook JA: Endothelial progenitor cells and a stromal cell-derived factor-1alpha analogue synergistically improve survival in sepsis. Am J Respir Crit Care Med 2014, 189(12):1509-1519.

16. Tianhang L, Bo W, Zhengmao L, Tao P, Hong Z, Xuchao X, Jianwei B, Hui Z, Guoen F: Autologous transplantation of endothelial progenitor cells to prevent multiple organ dysfunction syndromes in pig. J Trauma Acute Care Surg 2013, 74(2):508-515.

17. Mayr FB, Spiel AO, Leitner JM, Firbas C, Sieghart W, Jilma B: Effects of low dose endotoxemia on endothelial progenitor cells in humans. Atherosclerosis 2007, 195(1):e202-e206.

18. Kung CT, Su CM, Chen CT, Cheng HH, Chang MW, Hung CW, Hung SC, Chang WN, Tsai NW, Wang HC et al: Circulating endothelial progenitor cells may predict outcomes in adult patients with severe sepsis in the emergency department. Clin Chim Acta 2016, 455:1-6.

19. Jin Y, Yang C, Sui X, Cai Q, Guo L, Liu Z: Endothelial progenitor cell transplantation attenuates lipopolysaccharide-induced acute lung injury via regulating miR-10a/b-5p. Lipids Health Dis 2019, 18(1).

20. Yeh C, Pai M, Shih Y, Shih J, Yeh S: Intravenous Arginine Administration Promotes Proangiogenic Cells Mobilization and Attenuates Lung Injury in Mice with Polymicrobial Sepsis. Nutrients 2017, 9(5):507.

21. Patschan SA, Patschan D, Temme J, Korsten P, Wessels JT, Koziolek M, Henze E, Muller GA: Endothelial progenitor cells (EPC) in sepsis with acute renal dysfunction (ARD). Crit Care 2011, 15(2):R94.

22. Singer M, Deutschman CS, Seymour CW, Shankar-Hari M, Annane D, Bauer M, Bellomo R, Bernard GR, Chiche JD, Coopersmith CM et al: The Third International Consensus Definitions for Sepsis and Septic Shock (Sepsis-3). JAMA 2016, 315(8):801-810.

23. Asahara T, Murohara T, Sullivan A, Silver M, van der Zee R, Li T, Witzenbichler B, Schatteman G, Isner JM: Isolation of putative progenitor endothelial cells for angiogenesis. Science 1997, 275(5302):964-967.

24. Shmelkov SV, St CR, Lyden D, Rafii S: AC133/CD133/Prominin-1. Int J Biochem Cell Biol 2005, 37(4):715-719.

25. Rafat N, Hanusch C, Brinkkoetter PT, Schulte J, Brade J, Zijlstra JG, van der Woude FJ, van Ackern K, Yard BA, Beck GC: Increased circulating endothelial progenitor cells in septic patients: Correlation with survival. Crit Care Med 2007, 35(7):1677-1684.

26. Marshall JC: Endotoxin in the pathogenesis of sepsis. Contrib Nephrol 2010, 167:1-13.

27. Mutunga M, Fulton B, Bullock R, Batchelor A, Gascoigne A, Gillespie Jl, Baudouin SV: Circulating endothelial cells in patients with septic shock. Am J Respir Crit Care Med 2001, 163(1):195-200.

28. Fan H, Goodwin AJ, Chang E, Zingarelli B, Borg K, Guan S, Halushka PV, Cook JA: Endothelial Progenitor Cells and a Stromal Cell-derived Factor-1a Analogue Synergistically Improve Survival in Sepsis. Am J Resp Crit Care 2014, 189(12):1509-1519.

29. Yang N, Tian H, Zhan E, Zhai L, Jiao P, Yao S, Lu G, Mu Q, Wang J, Zhao A et al: Reverse-D-4F improves endothelial progenitor cell function and attenuates LPS-induced acute lung injury. Respir Res 2019, 20(1):131.

30. Zahran AM, Elsayh KI, Mohamad IL, Hassan GM, Abdou MA: Circulating Endothelial Cells and Endothelial Progenitor Cells in Pediatric Sepsis. Pediatr Emerg Care 2016, 32(3):163-167.

31. Becchi C, Pillozzi S, Fabbri LP, Al MM, Cacciapuoti C, Della BC, Nucera M, Masselli M, Boncinelli S, Arcangeli A et al: The increase of endothelial progenitor cells in the peripheral blood: a new parameter for detecting onset and severity of sepsis. Int $\mathrm{J}$ Immunopathol Pharmacol 2008, 21(3):697-705.

Page $7 / 14$ 
32. Menchinelli G, Liotti FM, Fiori B, De Angelis G, D'Inzeo T, Giordano L, Posteraro B, Sabbatucci M, Sanguinetti M, Spanu T: In vitro Evaluation of BACT/ALERT ${ }^{\circledR}$ VIRTUO ${ }^{\circledR}$, BACT/ALERT 3D $®$, and BACTEC ${ }^{\text {Tm }}$ FX Automated Blood Culture Systems for Detection of Microbial Pathogens Using Simulated Human Blood Samples. Front Microbiol 2019, 10.

\section{Table}

Table 1. Demographic and clinical characteristics of the studied septic patients and the healthy controls.

\begin{tabular}{|c|c|c|c|c|c|c|c|c|c|}
\hline & Group & & & Group & & & Group & & \\
\hline $\begin{array}{l}\text { Characteristics } \\
N(\%) \text { OR mean } \pm \\
\text { SD }\end{array}$ & Control & All patients & $\begin{array}{l}\mathrm{P} \text { - } \\
\text { value }\end{array}$ & Sepsis & $\begin{array}{l}\text { Septic } \\
\text { shock }\end{array}$ & $\begin{array}{l}\mathrm{P}- \\
\text { value }\end{array}$ & Survivors & $\begin{array}{l}\text { Non- } \\
\text { survivors }\end{array}$ & $\begin{array}{l}\mathrm{P} \text { - } \\
\text { value }\end{array}$ \\
\hline $\begin{array}{l}\text { Number of } \\
\text { subjects }\end{array}$ & 20 & 39 & - & $23(59.0 \%)$ & $16(41.0 \%)$ & - & $27(69.2 \%)$ & $12(30.8 \%)$ & - \\
\hline Age & $59.4 \pm 6.2$ & $63.3 \pm 13.1$ & NS & $65.4 \pm 11.8$ & $60.1 \pm 14.6$ & NS & $60.2 \pm 14.1$ & $70.2 \pm 7.2$ & NS \\
\hline Sex (M) & $10 \rrbracket 50 \% \rrbracket$ & $23 \rrbracket 59.0 \% \rrbracket$ & NS & $15 \rrbracket 65.2 \% \rrbracket$ & $7 \rrbracket 43.8 \% \rrbracket$ & NS & $16 \rrbracket 59.3 \% \rrbracket$ & $6 \rrbracket 50 \% \rrbracket$ & NS \\
\hline $\begin{array}{l}\text { Hospital } \\
\text { mortality }\end{array}$ & - & $12 \varangle 30.8 \% \rrbracket$ & - & $7 \rrbracket 30.4 \% \rrbracket$ & $5(31.3 \%)$ & NS & - & - & - \\
\hline 7-day mortality & - & 6冈15.4\%】 & - & $4(17.4 \%)$ & $2(12.5 \%)$ & NS & - & - & - \\
\hline ICU LOS (days) & - & $8.5 \pm 6.6$ & - & $7.6 \pm 5.5$ & $9.8 \pm 7.9$ & NS & $8.4 \pm 5.9$ & $8.6 \pm 8.1$ & NS \\
\hline $\begin{array}{l}\text { Hospital LOS } \\
\text { (days) }\end{array}$ & - & $21.3 \pm 23.0$ & - & $22.6 \pm 28.0$ & $19.4 \pm 13.6$ & NS & $25.4 \pm 25.1$ & $12.2 \pm 14.6$ & $\llbracket 0.01$ \\
\hline \multicolumn{10}{|l|}{ Type of infection } \\
\hline Pneumonia & - & $7 \rrbracket 17.9 \% \bigotimes$ & - & $7(30.4 \%)$ & $0(0 \%)$ & - & $5(18.5 \%)$ & $2(16.7 \%)$ & - \\
\hline Urethritis & - & $4 \rrbracket 10.3 \% \rrbracket$ & - & $1(4.3 \%)$ & $3(18.7 \%)$ & - & $3(11.1 \%)$ & $1(8.3 \%)$ & - \\
\hline Peritonitis & - & $17 \rrbracket 43.6 \% \rrbracket$ & - & $10(43.5 \%)$ & $7(43.8 \%)$ & - & $13(48.2 \%)$ & $4(33.3 \%)$ & - \\
\hline Pancreatitis & - & $3 \otimes 7.7 \% \rrbracket$ & - & 1 & $2(12.5 \%)$ & - & $2(7.4 \%)$ & 1 & - \\
\hline $\begin{array}{l}\text { Skin and soft } \\
\text { tissue }\end{array}$ & - & $3 \rrbracket 7.7 \% \rrbracket$ & - & 1 & $2(12.5 \%)$ & - & $2(7.4 \%)$ & 1 & - \\
\hline Others & - & $5 \rrbracket 12.8 \% \rrbracket$ & - & 3 & $2(12.5 \%)$ & - & $2(7.4 \%)$ & 3 & - \\
\hline \multirow{2}{*}{$\begin{array}{l}\text { Positive blood } \\
\text { cultures Gram } \\
\text { positive/negative }\end{array}$} & - & $18 \otimes 46.2 \% \rrbracket$ & - & $11(47.8 \%)$ & $7(43.8 \%)$ & NS & $11(40.7 \%)$ & $7(58.3 \%)$ & NS \\
\hline & - & $5 / 13$ & - & $3 / 8$ & $2 / 5$ & - & $3 / 8$ & $2 / 5$ & - \\
\hline APACHE II & - & $20.3 \pm 8.3$ & - & $18.2 \pm 8.8$ & $23.3 \pm 6.6$ & $\otimes 0.05$ & $17.5 \pm 7.5$ & $26.6 \pm 6.4$ & $\varangle 0.01$ \\
\hline SOFA & - & $6.8 \pm 3.3$ & - & $5.1 \pm 2.5$ & $9.2 \pm 2.8$ & $\otimes 0.01$ & $6.4 \pm 3.3$ & $7.6 \pm 3.3$ & NS \\
\hline Lactate $(\mathrm{mg} / \mathrm{dl})$ & - & $2.8 \pm 2.3$ & - & $2.1 \pm 1.3$ & $3.8 \pm 3.1$ & $\otimes 0.05$ & $2.4 \pm 1.6$ & $3.7 \pm 3.5$ & NS \\
\hline CRP (mg/l) & - & $158.1 \pm 121.4$ & - & $146.6 \pm 117.2$ & $174.8 \pm 129.1$ & NS & $168.6 \pm 104.2$ & $134.7 \pm 156.0$ & NS \\
\hline РСТ (ng/ml) & - & $41.3 \pm 63.7$ & - & $26.4 \pm 50.1$ & $62.6 \pm 75.9$ & $\otimes 0.05$ & $37.0 \pm 56.2$ & $50.9 \pm 80.0$ & NS \\
\hline WBC $\left(\times 10^{9} / \mathrm{I}\right)$ & $6.1 \pm 1.8$ & $11.8 \pm 7.1$ & $\varangle 0.01$ & $12.7 \pm 8.1$ & $10.5 \pm 5.3$ & NS & $12.5 \pm 6.5$ & $10.3 \pm 8.4$ & NS \\
\hline Plt $\left(\times 10^{9} / \mathrm{l}\right)$ & $241.2 \pm 72.6$ & $126.8 \pm 65.8$ & $\varangle 0.01$ & $137.0 \pm 73.9$ & $112.1 \pm 50.6$ & $₫ 0.05$ & $131.8 \pm 70.2$ & $115.5 \pm 55.6$ & NS \\
\hline $\mathrm{Hb}(\mathrm{mg} / \mathrm{dl})$ & $141.2 \pm 17.1$ & $121.6 \pm 22.0$ & 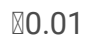 & $121.1 \pm 21.7$ & $122.3 \pm 23.1$ & NS & $120.9 \pm 18.7$ & $123.1 \pm 29.0$ & NS \\
\hline
\end{tabular}

ICU LOS:length of stay in the intensive care unit; Hospital LOS:length of stay in hospital; APACHE II: Acute Physiology and Chronic Health Evaluation II; SOFA: Sequential Organ Failure Assessment; CRP: C-Reactive Protein; PCT: Procalcitonin; WBC: White Blood Cell; Plt: Platelet; Hb: Hemoglobin. 

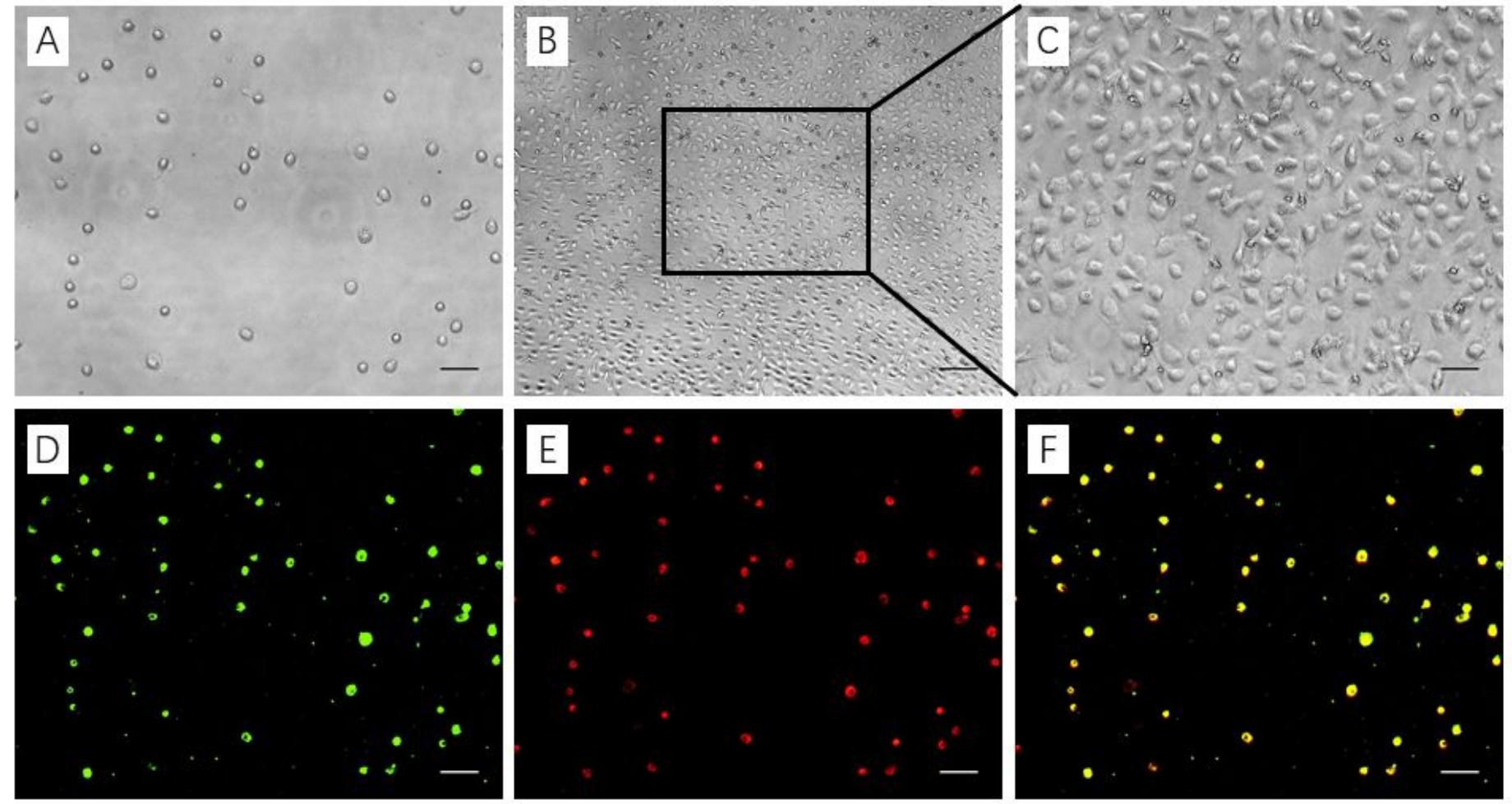

Figure 1

Morphology and characterization of EPCs derived from human peripheral blood. A: EPCs under a light microscope cultured for 7 days; D:EPCs binding FITC-UEA-1; E: EPCs adsorption of Dil-ac-LDL; F:Merged image of D and E; B and C: EPCs showed a cobblestone-like morphology cultured for 10 days in EGM-2 medium. Scale bar, $A \& C-F=100 \mu m, B=250 \mu m$.

A

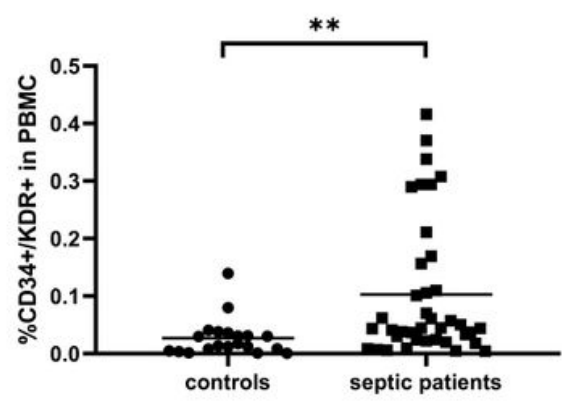

D

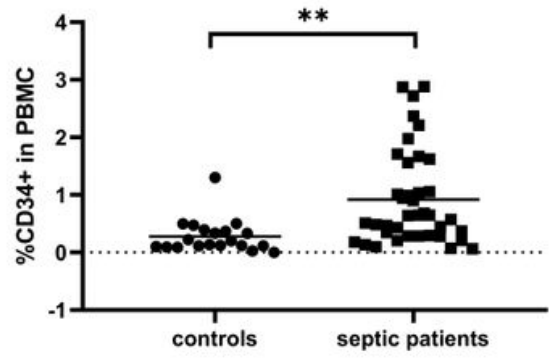

B

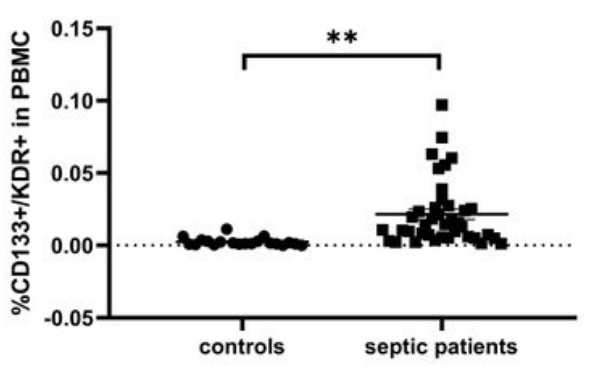

E

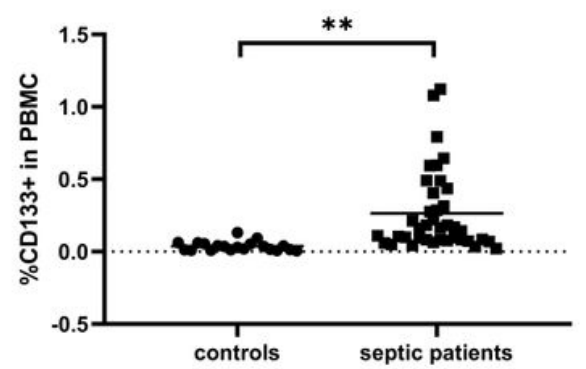

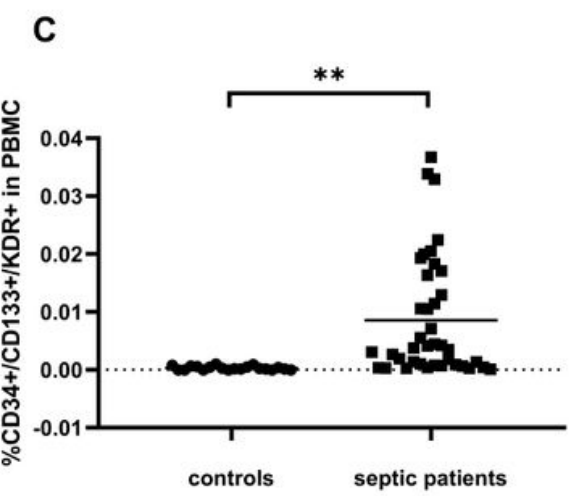

F

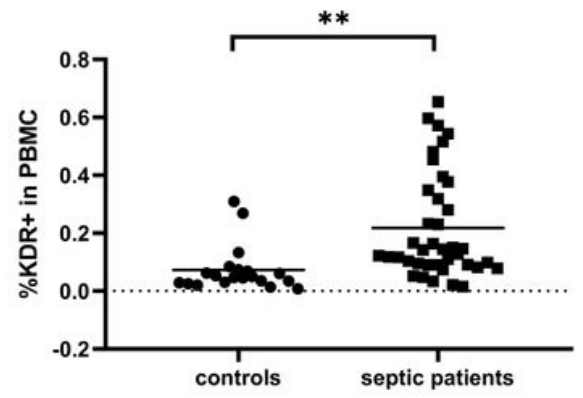


Figure 2

The number of EPCs in septic patients was more than that in healthy controls. FACS analysis of the percentages of six subpopulations of progenitor cells in peripheral blood mononuclear cell (PBMC) of healthy controls and septic patients. A CD34+/KDR+ (\%), B CD133+/KDR+ (\%), C CD34+/CD133+/KDR+ (\%), D CD34+ (\%), E CD133+ (\%), F KDR+ (\%). Significant differences were found between the two groups. Data were given as mean $\pm \operatorname{SEM}(* * \mathrm{P}<0.01)$.

A

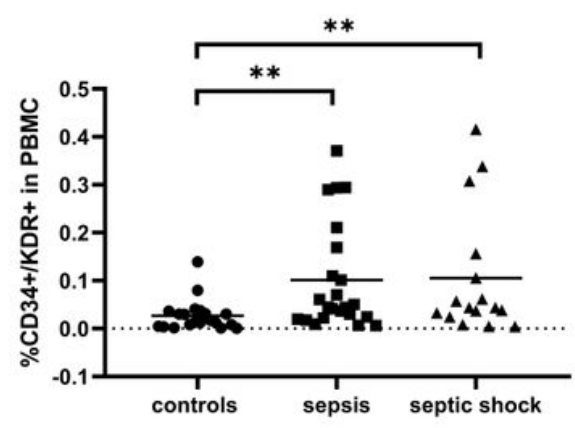

D

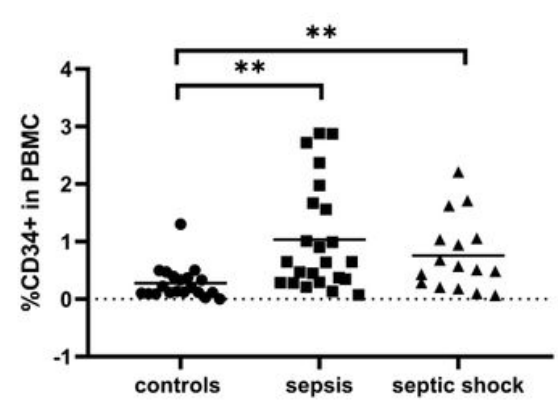

B

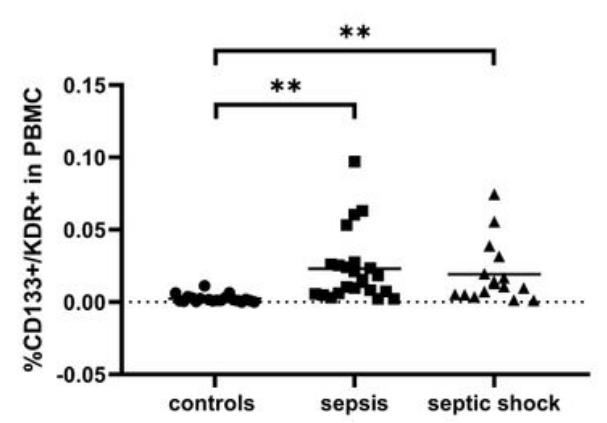

E

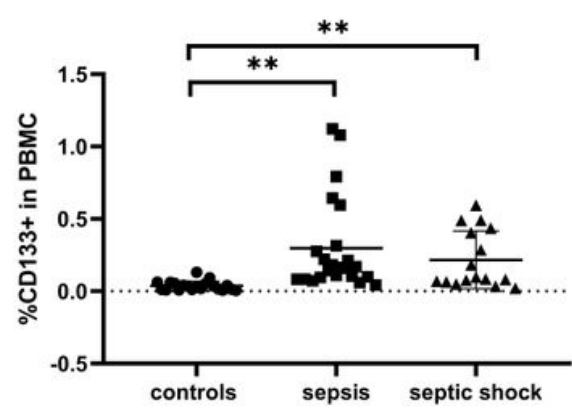

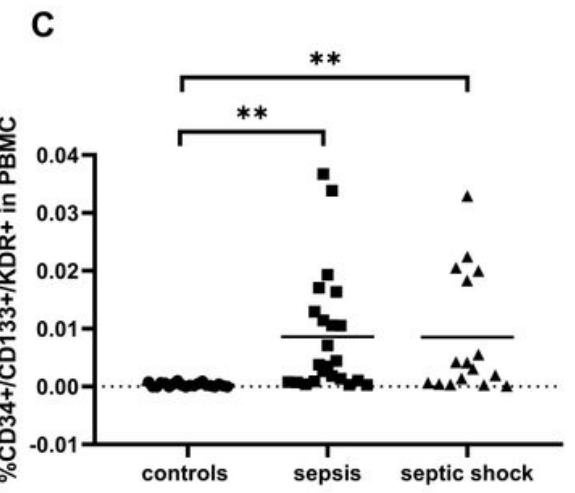

F

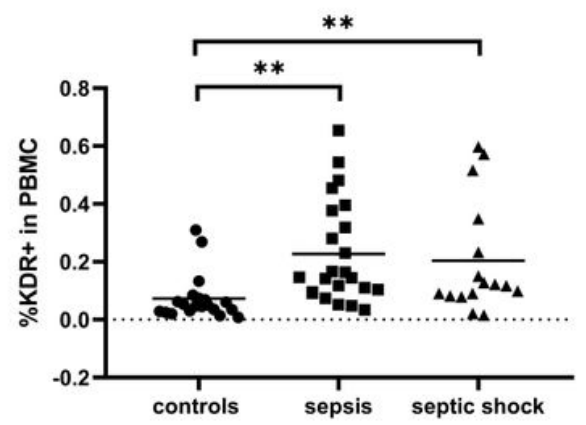

Figure 3

The number of EPCs in sepsis group were similar as that in septic shock group. The percentages of progenitor cells in healthy controls , sepsis group and septic shock group. A CD34+/KDR+ (\%), B CD133+/KDR+ (\%), C CD34+/CD133+/KDR+ (\%), D CD34+ (\%), E CD133+ (\%), F KDR+ (\%). Data were given as mean $\pm \operatorname{SEM}(* * \mathrm{P}<0.01)$. 
A

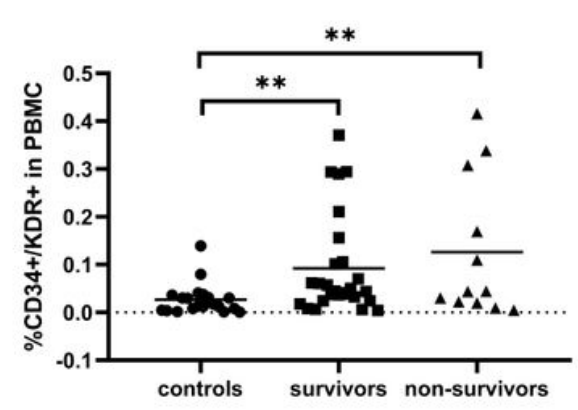

D

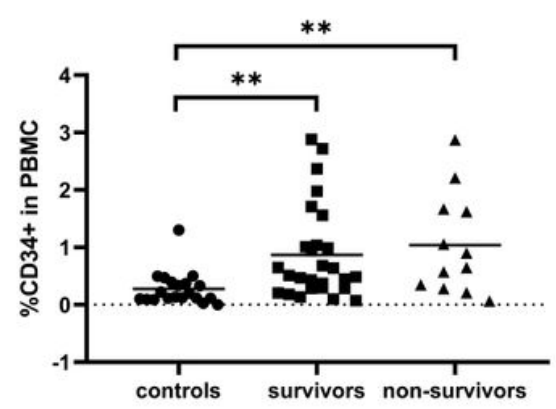

B

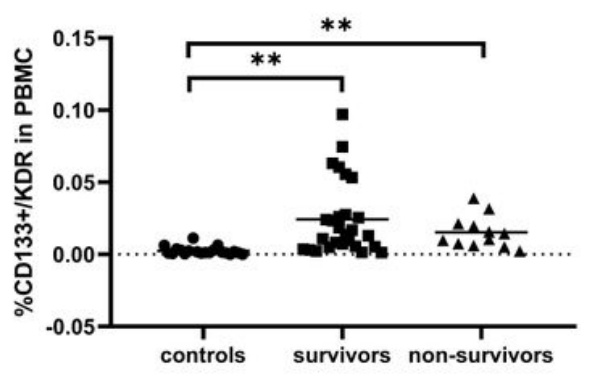

E

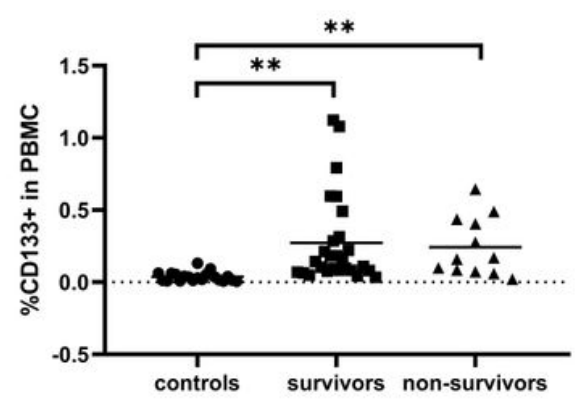

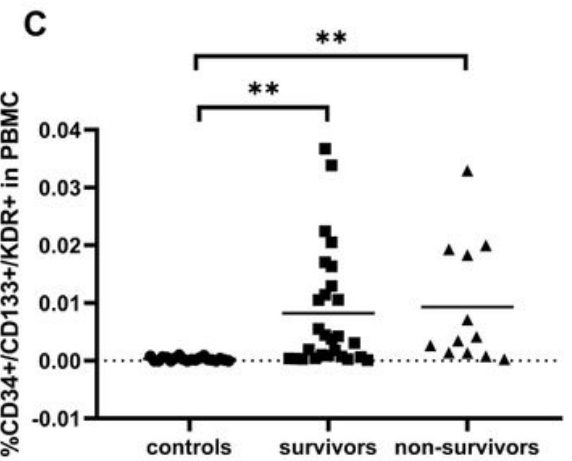

$\mathbf{F}$

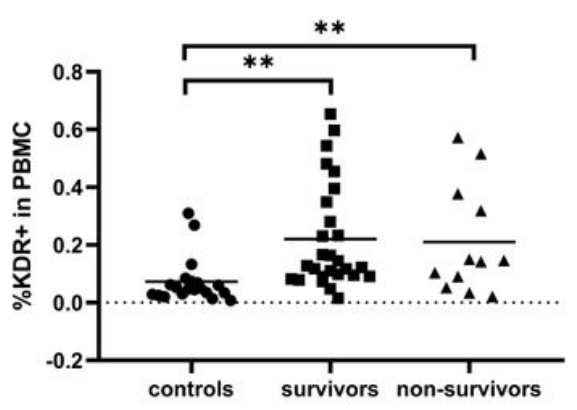

Figure 4

The number of EPCs in survival group were similar as that in non-survival group. The percentages of progenitor cells in healthy controls , survival group and non-survival group. A CD34+/KDR+ (\%), B CD133+/KDR+ (\%), C CD34+/CD133+/KDR+ (\%), D CD34+ (\%), E CD133+ (\%), F $\mathrm{KDR}+(\%)$. Data were given as mean $\pm \mathrm{SEM}(* \star \mathrm{P}<0.01)$. 
A

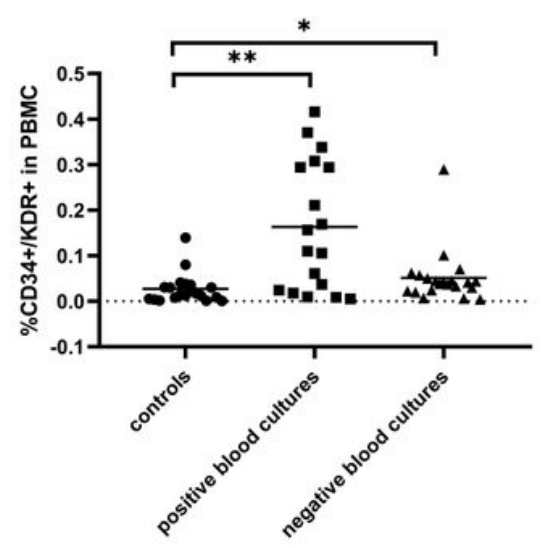

D

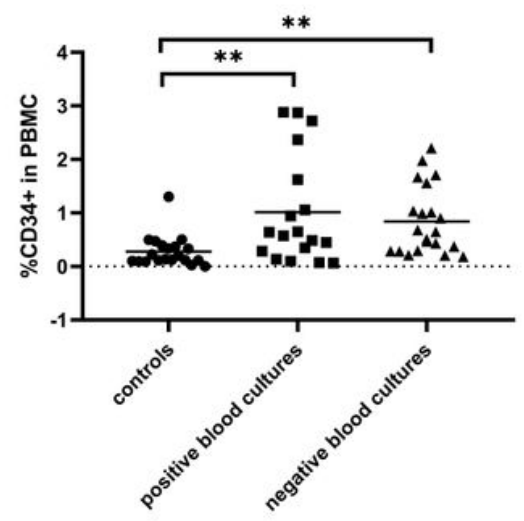

B

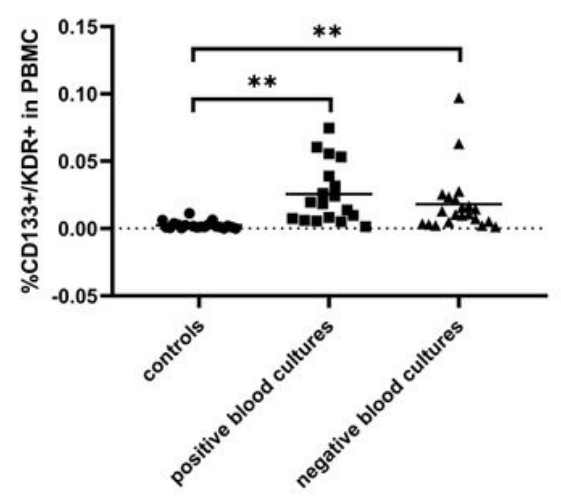

E

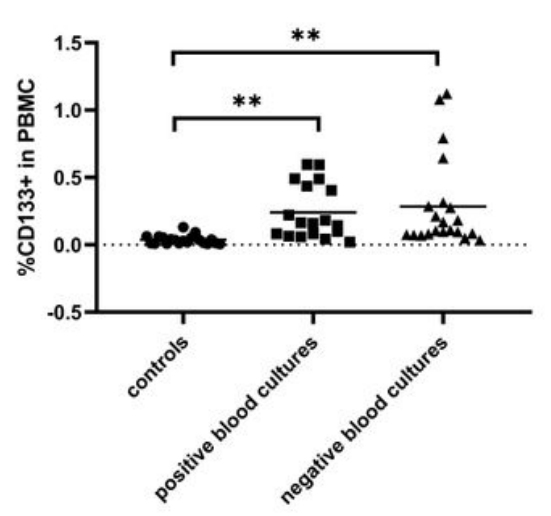

C

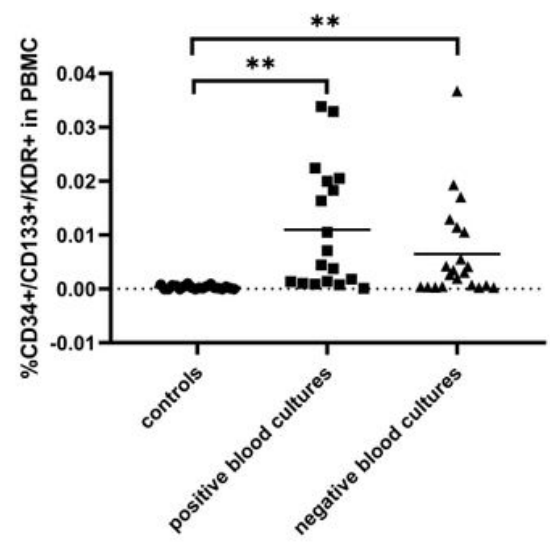

$\mathbf{F}$

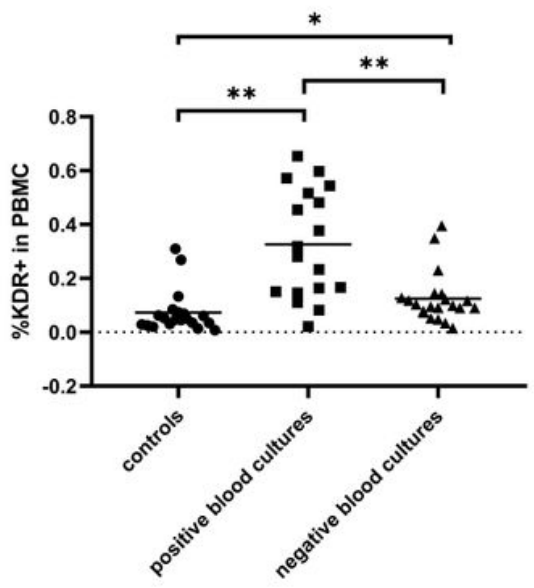

Figure 5

The number of EPCs were different respectively in groups according to blood culture. The percentages of progenitor cells were showed in positive blood cultures group, negative blood cultures group and healthy controls. A CD34+/KDR+ (\%), B CD133+/KDR+ (\%), C $\mathrm{CD} 34+/ \mathrm{CD} 133+/ \mathrm{KDR}+(\%), \mathrm{D} C D 34+(\%), \mathrm{E} \mathrm{CD133+} \mathrm{( \% ),} \mathrm{F} \mathrm{KDR}+(\%)$. Data were given as mean $\pm \mathrm{SEM}\left({ }^{\star} \mathrm{P}<0.05,{ }^{\star \star P}<0.01\right)$. 
A

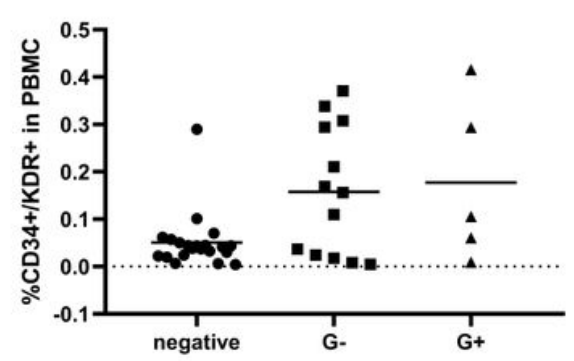

D

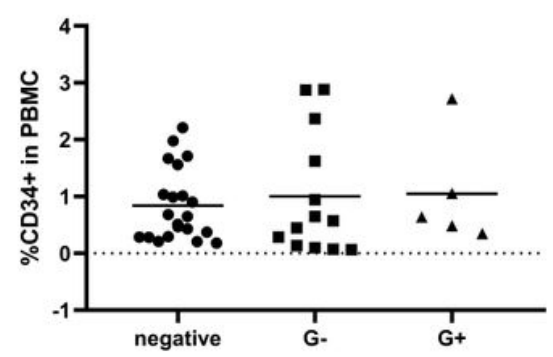

B

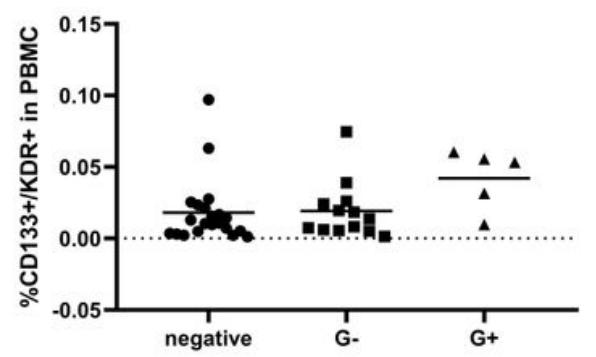

E

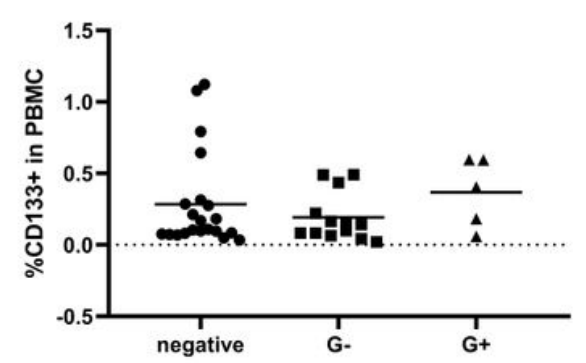

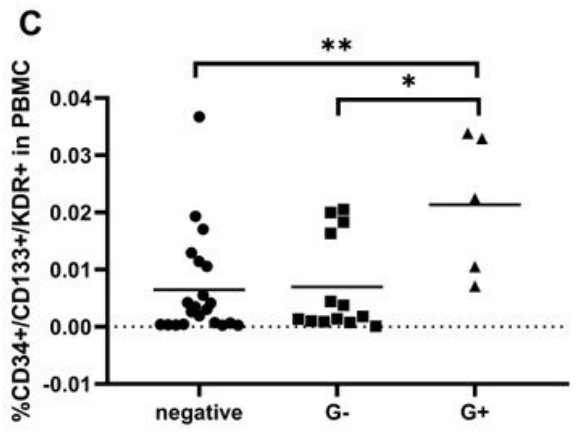

F

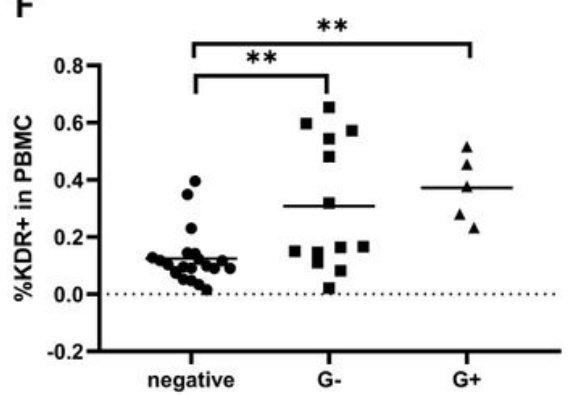

Figure 6

The number of EPCs were different respectively in groups according to infectious organisms. The percentages of six subpopulations of progenitor cells in PBMC were showed in Gram-positive bacteremia group, Gram-negative bacteremia group, and negative blood culture group. A CD34+/KDR+ (\%), B CD133+/KDR+ (\%), C CD34+/CD133+/KDR+ (\%), D CD34+ (\%), E CD133+ (\%), F KDR+ (\%). Data were given as mean $\pm \operatorname{SEM}\left({ }^{\star} \mathrm{P}<0.05\right.$, $\left.{ }^{\star \star} \mathrm{P}<0.01\right)$. 
A

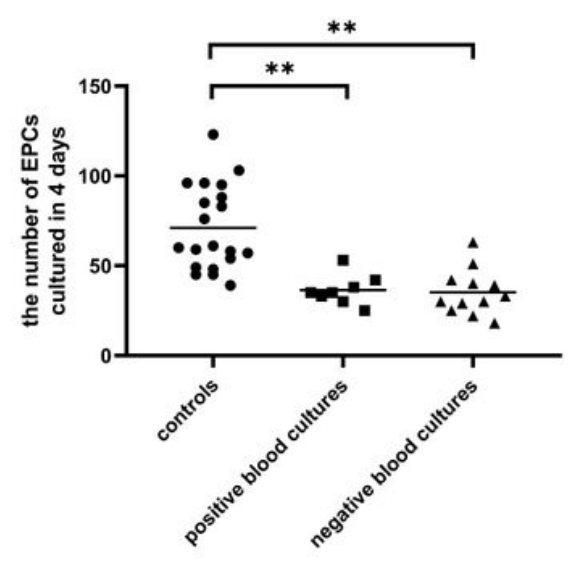

D

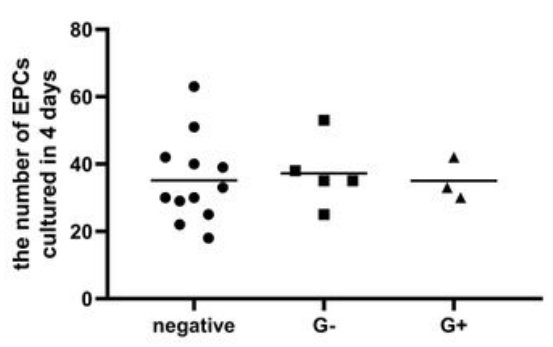

B

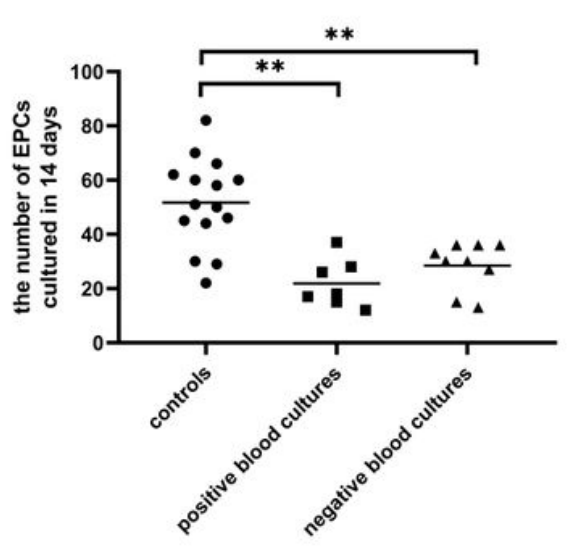

E

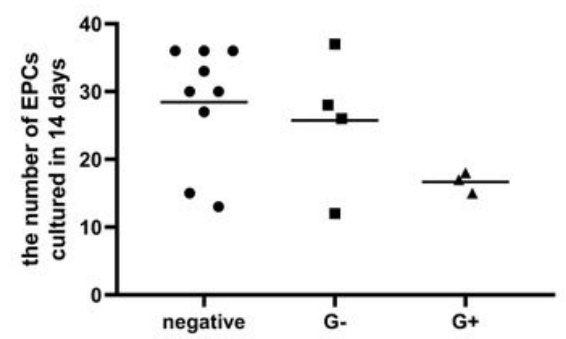

C

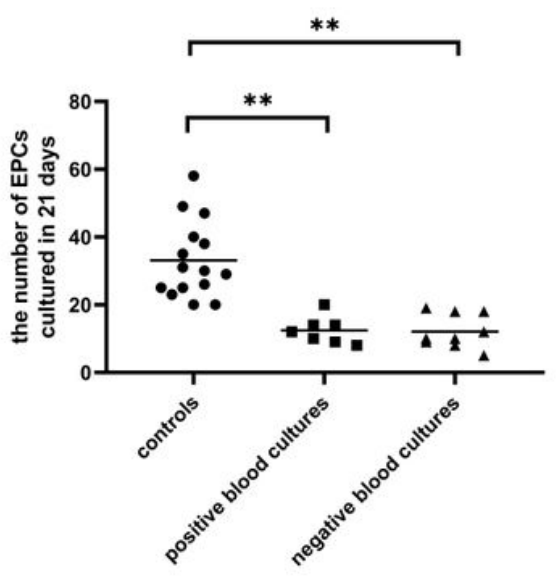

$\mathbf{F}$

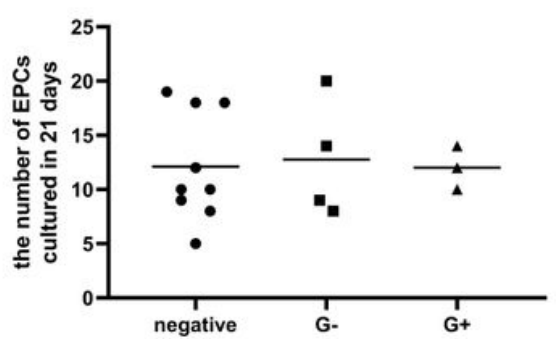

Figure 7

The number of cultured EPCs in healthy controls was significantly more than septic patients. The mononuclear cells derived from patients' peripheral blood were cultured on fibronectin-coated plates, and the number of EPCs were counted on 4,14 and 21 days respectively. A-C: The number of EPCs in positive blood cultures, negative blood group and heathy controls. D-F: The number of EPCs in Gram-positive bacteremia group, Gram-negative bacteremia group, and negative blood culture group. Data were given as mean $\pm S D(\star \star P<0.01)$. 